\title{
High-dose Accelerated vs Low-dose Frequent Regime of Iron Sucrose Therapy in Antenatal and Postnatal Women with Iron Deficiency
}

\author{
${ }^{1}$ Shaheen Anjum, ${ }^{2}$ Nidhi Garg, ${ }^{3}$ Sri Beriwal, ${ }^{4}$ Anjum Parvez
}

\begin{abstract}
Objective: To compare an accelerated high-dose (500 mg) vs low-dose $(200 \mathrm{mg}$ ) regimen of intravenous iron sucrose in a cohort of iron-deficient anemic antenatal patients in terms of efficacy, safety, and compliance.

Materials and methods: In a prospective hospital-based study, antenatal and postnatal women with anemia attending Jawaharlal Nehru Medical College and Hospital, Aligarh, India, between December 2010 and December 2012 were enrolled. The inclusion criteria were all outpatient and admitted anemic antenatal women $\leq 36$ weeks gestation and postnatal women with hemoglobin $(\mathrm{Hb})$ below $10 \mathrm{gm} / \mathrm{dL}$, or serum ferritin $\leq 30 \mu \mathrm{g} / \mathrm{L}$ or transferrin saturation $\leq 40 \%$ irrespective of prior oral iron therapy. Patients were excluded from the study if they were hemodynamically unstable, actively bleeding, having fever, or were nauseated or vomiting. Participants were assigned to control and study groups according to simple random sampling. Intravenous iron sucrose group I (500 mg)/group II (200 mg) was infused after test dose on alternate days for the calculated total dose in the study population. Blood and iron indices were measured at baseline and after 2 weeks of administration of last dose. The primary outcome of the study was to assess the rise in $\mathrm{Hb}$ and safety of high-dose intravenous iron sucrose.
\end{abstract}

Results: There was a statistically significant increase in $\mathrm{Hb}$ level in patients receiving either regimen, with larger mean increase in group I $(2.7 \pm 0.4)$ compared with group II $(2.25 \pm$ 6.39). Serum iron and serum ferritin also increased in both fortnightly $(p<0.001)$. Blood transfusion was avoided by $90.1 \%$ in severely anemic cases with $\mathrm{Hb}<7$. Hospital stay was reduced by $50 \%$ in group I.

Conclusion: The accelerated regimen of high-dose $(500 \mathrm{mg})$ intravenous iron sucrose in anemic antenatal patients appears to be safe and effective in correcting anemia, restoring iron stores, and avoiding blood transfusion.

Keywords: Anemia, Iron deficiency, Iron sucrose.

${ }^{1}$ Professor, ${ }^{2,3}$ Postgraduate Student, ${ }^{4}$ Associate Professor

${ }^{1-3}$ Department of Obstetrics and Gynecology, Jawaharlal Nehru Medical College and Hospital, Aligarh Muslim University, Aligarh Uttar Pradesh, India

${ }^{4}$ Department of Medicine, Jawaharlal Nehru Medical College and Hospital, Aligarh Muslim University, Aligarh, Uttar Pradesh, India

Corresponding Author: Shaheen Anjum, Professor, Department of Obstetrics and Gynecology, Jawaharlal Nehru Medical College and Hospital, Aligarh Muslim University, Aligarh, Uttar Pradesh, India, Phone: +919319861442, e-mail: shahanjum73@ gmail.com
How to cite this article: Anjum S, Garg N, Beriwal S, Parvez A. High-dose Accelerated vs Low-dose Frequent Regime of Iron Sucrose Therapy in Antenatal and Postnatal Women with Iron Deficiency. World J Anemia 2017;1(2):31-35.

Source of support: Nil

Conflict of interest: None

\section{INTRODUCTION}

Iron deficiency anemia is the most common cause of anemia in obstetrics. ${ }^{1}$ Efficacy of oral iron therapy is limited in many patients because of dose-dependent side effects, lack of compliance, and insufficient duodenal iron absorption. Rapid correction of anemia depends completely on blood transfusion, the hazards of which are well known. Newer parenteral preparations are being considered a safer therapy than blood transfusion. Administration of 100 to $200 \mathrm{mg}$ intravenous iron sucrose doses three times a week is an approved regimen by the Food and Drug Association (FDA). Although other high-dose scheme regimens have been published frequently for chronic kidney disease (CKD) patients, very few such dosing regimens are investigated in the obstetric population. ${ }^{2-4}$

High-dose iron sucrose therapy is now a known practice among nephrologists worldwide to manage anemia in dialysis patients even on consecutive day administration regimens. ${ }^{5-7}$ However, studies are lacking in obstetrics. This encouraged us to explore this high-dose $(500 \mathrm{mg})$ regimen in an effort not only to treat anemia effectively but also safely and rapidly comparable to that of blood transfusions, and to reduce the loss to follow-up seen with the low-dose (200 mg) regimen. Hence, we prospectively studied a high-dose $(500 \mathrm{mg}$ ) intravenous iron sucrose regimen utilizing an accelerated dosing frequency in antenatal and postnatal patients with iron deficiency anemia and compared it with a regimen of low-dose (200 $\mathrm{mg}$ ) iron therapy in a small cohort of patients. Additionally, we compared the efficacy, safety, and benefits of the high-dose regimen. ${ }^{8}$

\section{MATERIALS AND METHODS}

In this prospective study, the participants were recruited from patients seen by the Department of Obstetrics and 
Gynecology at Jawaharlal Nehru Medical College and Hospital in Aligarh, India, following approval from the ethics committee. This study was conducted over a 2-year period from December 2010 to December 2012. All anemic antenatal women at less than 36 weeks gestation and postnatal women were eligible if the $\mathrm{Hb}$ below $10 \mathrm{gm} / \mathrm{dL}$, or serum ferritin was below $30 \mathrm{\mu g} / \mathrm{L}$ or transferrin saturation was less than $40 \%$. This cohort consisted of both hospitalized patients and outpatients who may or may not have been already receiving oral iron therapy prior to the study. Any intolerance to either oral iron, reaction to blood transfusion, or intramuscular iron was not considered a contraindication for participation in this study. Patients were excluded from the study if they were hemodynamically unstable, actively bleeding, having fever, or were nauseated or vomiting. Anemia other than iron deficiency anemia was diagnosed and appropriately treated. Patients did not receive red blood cell transfusion for 1 week prior to or during the study period.

After explaining to the patients about the intervention properly, consent was taken. A test dose was administered with $1 \mathrm{~mL}(25 \mathrm{mg}) 10 \%$ solution intravenously prior to the total dose infusion (TDI) which was calculated by the formula below: ${ }^{9}$

Total dose infusion $=$ body weight $(\mathrm{kg}) \times \mathrm{Hb}$ deficit (target-actual in $\mathrm{gm} / \mathrm{dL}) \times 2.4+$ iron stores $(500 \mathrm{mg})$

The dosing regimen employed two doses of intravenous iron sucrose: $500 \mathrm{mg}$ diluted in $250 \mathrm{~mL}$ in group I or $200 \mathrm{mg}$ diluted in $100 \mathrm{~mL}$ of normal saline solution in group II and infused over 4 hours on alternating days. Total dose calculated from the TDI formula mostly required two doses of $500 \mathrm{mg}$ infusion and five or more doses of $200 \mathrm{mg}$ infusions. Vital signs were monitored throughout the administration. Any adverse events occurring during or after the infusion were recorded. Prior to administration, baseline data included the gravid state, $\mathrm{Hb}$, red blood indices including mean corpuscular volume, mean corpuscular $\mathrm{Hb}$, and mean corpuscular $\mathrm{Hb}$ concentration, and serum ferritin and iron. Further data were determined after 2 weeks of the final dose. Rate of blood transfusion avoided was also noted along with the number of days of hospital stay in both regimens.

Samples for $\mathrm{Hb}$ and red blood indices were collected in AkUret K2EDTA vials. Samples for iron indices were collected in AkUret red vials, which are silicon-coated to avoid red blood cell adherence to the wall of the tube. Hemoglobin and blood indices were calculated using an automated Hematology Analyzer Premiere Diagnova with the colorimetric and impedance methods respectively. Serum ferritin was estimated by enzyme-linked immunosorbent assay technique using the quantitative test kit.
All patients were administered prophylactic dose of an antihelminthic (albendazole $400 \mathrm{mg}$ ) due to Aligarh being in high endemic region for the same.

All values were expressed as means and standard deviations. Values were compared fortnightly.

\section{Statistical Analysis}

The categorical variables were compared using the chisquare test. The unpaired t-test was used to compare independent means and the paired t-test was used to compare means before and after treatment. The relative risk with its $95 \%$ confidence interval (CI) was calculated to find out the relative importance of the variable. The p-value $<0.001$ was considered significant. Statistical Package for the Social Sciences version 20 was employed for analysis.

\section{RESULTS}

Initially, 120 cases were enrolled for parenteral iron sucrose supplementation. However, there were 13 cases lost to follow-up in the initial stage, and thus, remaining 107 cases were evaluated among which after simple random sampling group I included 77 patients and group II included 31 patients. Table 1 depicts baseline clinical characteristics, which were comparable for both the groups. In the analysis of variance, repeated measures found a significant effect of time for $\mathrm{Hb}$ as well as for ferritin $(\mathrm{p}<0.001)$. The serum $\mathrm{Hb}$ increased from a baseline in both groups fortnightly after the last dose; however, the rise observed in group I cohort was higher with a mean difference of $2.7 \pm 0.400 \mathrm{gm} / \mathrm{dL}$ compared with $2.25 \pm 0.639 \mathrm{gm} / \mathrm{dL}$ in group II cohort, with this difference between the mean rise among both groups being highly statistically significant $(\mathrm{p}<0.001)$. The ferritin too increased significantly in both cohorts. In contrast to that in $\mathrm{Hb}$, the rise in ferritin was higher in group I compared with group II as depicted in Table 2. However, both groups could replenish stores by achieving a value above $30 \mu \mathrm{g} / \mathrm{L}$.

Group I completed the TDI in two to three doses compared with a much higher frequency of dosing in group II. Additionally, only $<20 \%$ of cases in group II completely

Table 1: Baseline characteristics

\begin{tabular}{lll}
\hline Baseline characteristics & Group I $(n=77)$ & Group II $(n=31)$ \\
\hline $\begin{array}{l}\text { Age of the patient, years } \\
\text { Gestational age }\end{array}$ & $24.1 \pm 3.1$ & $23.8 \pm 2.8$ \\
Gravidity & $31.6 \pm 3.4$ & $32.4 \pm 2.3$ \\
1 & & \\
$2-4$ & $12(15.6)$ & $4(13)$ \\
$\geq 5$ & $58(75.3)$ & $24(77.4)$ \\
$\mathrm{Hb}(\mathrm{gm} \%)$ on admission & $7(9.1)$ & $3(9.6)$ \\
\hline
\end{tabular}


Table 2: Pre- and posttherapy laboratory investigations in both cohorts

\begin{tabular}{|c|c|c|c|}
\hline & $\begin{array}{l}\text { Group I } \\
(n=77)\end{array}$ & $\begin{array}{l}\text { Group II } \\
(n=31)\end{array}$ & $p$-value ${ }^{1}$ \\
\hline $\mathrm{Hb}(\mathrm{gm} / \mathrm{dL})$ before & $6.45 \pm 1.14$ & $6.26 \pm 0.97$ & 0.42 \\
\hline $\mathrm{Hb}(\mathrm{gm} / \mathrm{dL})$ after & $9.15 \pm 1.35$ & $8.51 \pm 1.49$ & $0.04^{*}$ \\
\hline $\begin{array}{l}\mathrm{Hb}(\mathrm{gm} / \mathrm{dL}) \text { mean } \\
\text { difference }\end{array}$ & $2.7 \pm 0.4$ & $2.25 \pm 0.639$ & $<0.0001^{*}$ \\
\hline $\begin{array}{l}\text { Ferritin }(\mu \mathrm{g} / \mathrm{L}) \\
\text { before }\end{array}$ & $20.31 \pm 9.44$ & $19.48 \pm 10.52$ & 0.69 \\
\hline Ferritin $(\mu \mathrm{g} / \mathrm{L})$ after & $54.68 \pm 36.01$ & $72.48 \pm 52.20$ & $0.04^{*}$ \\
\hline $\begin{array}{l}\text { Ferritin }(\mu \mathrm{g} / \mathrm{L}) \\
\text { mean difference }\end{array}$ & $34.37 \pm 8.39$ & $53 \pm 19.14$ & $<0.0001^{*}$ \\
\hline$p$-value ${ }^{2}$ & $<0.0001^{*}$ & $<0.0001^{*}$ & \\
\hline
\end{tabular}

${ }^{1}$ Unpaired t-test; ${ }^{2}$ paired t-test; *significant

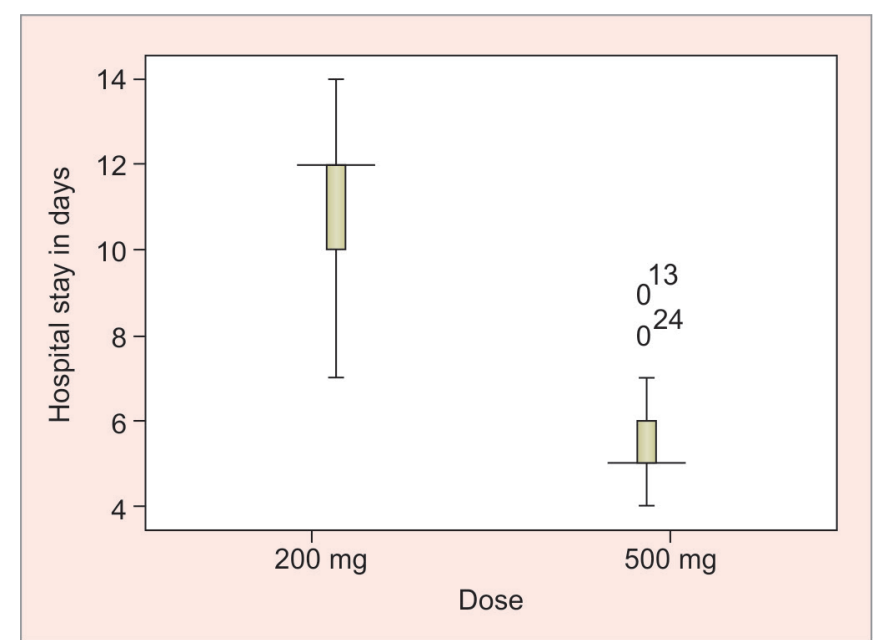

Graph 2: Comparison of hospital stay between groups II and I

received the TDI compared with $>90 \%$ of cases in group I, who received two doses of $500 \mathrm{mg}$ iron sucrose.

In our study, we observed the side effects among both groups in the form of occasional nausea and thrombophlebitis and found that $93.5 \%$ of cases who received the $500 \mathrm{mg}$ accelerated dose regimen reported no side effects. Thrombophlebitis was reported in $64.5 \%$ of cases receiving the $200 \mathrm{mg}$ frequent dosing regimen compared with only $5.2 \%$ of cases receiving the $500 \mathrm{mg}$ iron sucrose (Graph 1). The duration of hospital stay was significantly less in group I: $5.56 \pm 0.97$ compared with $11.31 \pm 1.63$ days in group II, which was highly statistically significant $(\mathrm{p}<0.001)$. Graph 2 depicts the same in the CI graph.

The efficacy of iron sucrose in avoiding blood transfusion was, however, observed in totality where $90.1 \%$ cases with $\mathrm{Hb}<7 \mathrm{gm} / \mathrm{dL}$ could avoid blood transfusion. All cases with $\mathrm{Hb}<5 \mathrm{gm} / \mathrm{dL}$ administered either $200 \mathrm{mg}$ frequent doses or accelerated $500 \mathrm{mg}$ doses could rise to levels above $7 \mathrm{gm} / \mathrm{dL}$ and hence avoided blood transfusion as depicted in Graph 3.

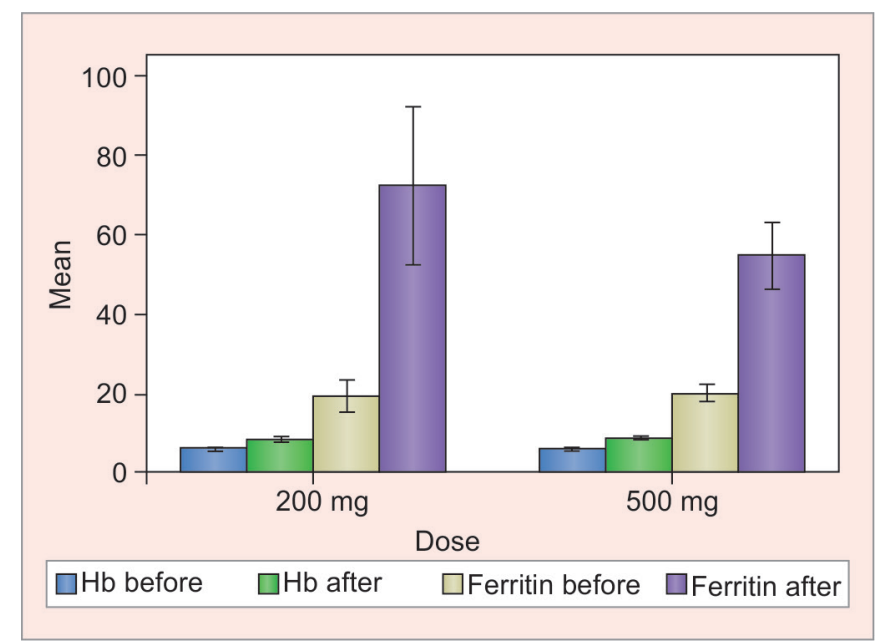

Graph 1: Comparison of ferritin and $\mathrm{Hb}$ level of cohorts 200 and $500 \mathrm{mg}$

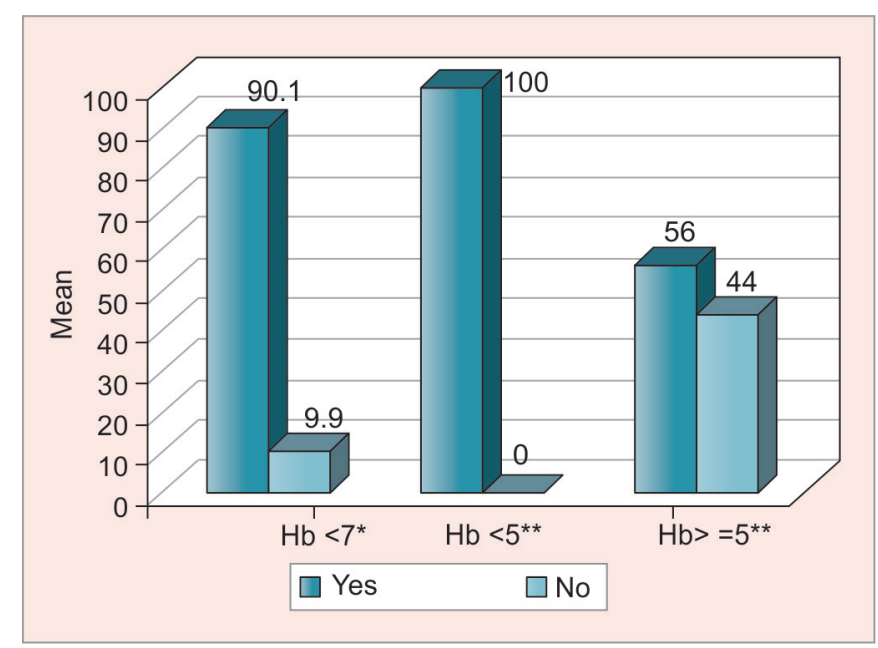

Graph 3: Blood transfusion avoided with therapy

\section{DISCUSSION}

The iron dosage regimes employed were effective in rapidly improving anemia, increasing stores, and avoiding blood transfusion. The $500 \mathrm{mg}$ accelerated dosing regimen was found to be not only an efficient and quicker way of improving iron status of our study population but also economical and safer when compared with the $200 \mathrm{mg}$ frequent dose regimen.

In our study, parenteral iron sucrose administration was started with a $200 \mathrm{mg}$ dose in a single infusion on an alternate-day basis for the calculated TDI. However, the rate of loss to follow-up, side effects, cost, and prolonged hospital stay due to the long duration of total therapy with the $200 \mathrm{mg}$ dose compelled us to administer the TDI in a short span. This observation compelled us to use an alternative approach of administering high-dose (500 mg) iron sucrose in a single infusion on alternate days (maximum three doses a week) for the completion of TDI.

Most cases in our study population were severely anemic with baseline $\mathrm{Hb}$ of less than $7 \mathrm{gm} / \mathrm{dL}$ according 
to the World Health Organization categorization. Both regimen patterns improved $\mathrm{Hb}$ levels from severe to moderate anemia, hence avoiding blood transfusion. However, the improvement seen in group I was greater. The rate of improvement of anemia was also observed to be faster as the values were estimated from a sample drawn 14 days after the last dose of TDI which was earlier for group I compared with group II.

The serum ferritin levels also increased enough to replenish stores. This rise in ferritin observed was more in group II than in group I. This could have resulted from the samples being drawn later in group II than those in group I, as the therapy lasted for a shorter duration in the latter.

Iron sucrose was well tolerated in the current study albeit in group I than in group II. The frequency of adverse events to the $500 \mathrm{mg}$ doses of iron sucrose has been reported to be highly variable, ranging from 0 to $36 \%$, mostly in the CKD population, ${ }^{7,9,10}$ making a safety evaluation difficult. In the current study, the rate of thrombophlebitis and concomitant number of IV cannulas changed throughout therapy were both markedly reduced after switching over to the $500 \mathrm{mg}$ dose regimen from the $200 \mathrm{mg}$ dose regimen. However, this was in contrast to a similar study where more phlebitis was seen after $500 \mathrm{mg}$ dose infusions in a small sample as compared with our study. ${ }^{3}$

The most positive effect with the $500 \mathrm{mg}$ dose regimen was a reduced hospital stay. It drastically reduced it from an average of $11.31 \pm 1.63$ to $5.56 \pm 0.97$ days, i.e., to half. This made the therapy popular among the target population. It can help cut down cost primarily and prevent chances of hospital-acquired infections secondarily.

Iron sucrose injection has been available for clinical use for more than 50 years. The dosing regimen specified is $100 \mathrm{mg}$ intravenously 1 to 3 times a week by the FDA. However, this regimen for the calculated TDI in obstetric patient with a limited time period of weeks is associated not only with failure to meet the target but also noncompliance due to the long duration of therapy. This encouraged us to explore this high dosage regimen in obstetrics.

High-dose iron sucrose therapy is now a well-known practice among nephrologists to manage anemia in dialysis cases even on consecutive day administration regimens..$^{5-7}$ Few attempts have been made to increase the dosage of iron sucrose and minimize the frequency of administration, simplifying the regimen for both the obstetrician and patients. ${ }^{2-4}$

Less frequent dosing could potentially increase the adherence to the medical regimen; there would be a less frequent need to obtain venous access, thereby decreasing side effects like thrombophlebitis, and a hematologic response might be hastened. Pharmacoeconomical advantages have also been proposed. ${ }^{11}$

To cut down cost and number of visits, high-dose (500 mg) iron sucrose weekly was compared with a $200 \mathrm{mg}$ dose in a study conducted in Pakistan, although on a smaller population. The rise in $\mathrm{Hb}$ was seen with both regimens but more with the $500 \mathrm{mg}$ dose in concurrence with the current study.

In another study on antenatal patients, researchers administered $400 \mathrm{mg}$ iron sucrose divided into two infusions daily in a small study population in order to administer the TDI over 5 days. ${ }^{2}$ More recently, a similar attempt with $400 \mathrm{mg}$ iron sucrose infusion in $250 \mathrm{~mL}$ normal saline given over half an hour or in two divided doses daily in postnatal cases was also proven to be safe and effective. ${ }^{4}$ Both these studies showed improvement in $\mathrm{Hb}$ levels in agreement with our study.

This study focuses on the safety of high-dose $(500 \mathrm{mg})$ iron sucrose infusion on alternate days in obstetric patients. The time period for administration of the TDI in antenatal patients is limited. Administering 100 to $200 \mathrm{mg}$ doses becomes impractical in severe anemia cases with a large calculated TDI due to noncompliance and side effects, and patients ultimately end up receiving blood transfusions.

The current study attempts to overcome this limitation by safely and effectively administering the total dose over a short duration without increasing any burden on patients in terms of time and money. The administration of $500 \mathrm{mg}$ iron sucrose on alternate days for the TDI was intended not only to treat anemia (correct $\mathrm{Hb}$ levels), but treat it safely (avoid blood transfusions) and replenish stores.

\section{CONCLUSION}

This study is the largest series examining high-dose (500 mg) iron sucrose therapy in obstetric patients especially antenatal. A large variety of patients were included to make it applicable to the obstetric patient population. Improvement in $\mathrm{Hb}$ and ferritin was achieved with decreased adverse effects and hospital visits. The accelerated high-dose regimen may improve the adherence of patients to therapy and also the burden on the health professionals, when compared with $200 \mathrm{mg}$ dose regimen.

\section{REFERENCES}

1. Cunninham, F.; Leveno, K.; Bloom, S. et al., editors. Williams obstetrics. New York: McGraw-Hill; 2010.

2. AlRA, Unlubilgin E, Kandemir O, Yalvac S, Cakir L, Haberal A. Intravenous versus oral iron for treatment of anemia in pregnancy: a randomized trial. Obstet Gynecol 2005 Dec;106(6):1335-1340. 
3. Wali A, Mushtaq A, Nilofer Comparative study-efficacy, safety and compliance of intravenous iron sucrose and intramuscular iron sorbitol in iron deficiency anemia of pregnancy. J Pak Med Assoc 2002 Sep;52(9):392-395.

4. Khamaiseh K, Tahat Y, Shreideh Z, Quran K. Intravenous iron sucrose versus blood transfusion in the management of symptomatic post partum iron deficiency anemia. J R Med Serv 2011 Mar;18(1):15-19.

5. Blaustein DA, Schwenk MH, Chattopadhyay J, Avram MM. Recent experience with high-dose intravenous iron administration. Kidney Int 2006 Dec;104(70): S26-S29.

6. Vikrant S, Pandey D. Safety and tolerability of high dose intravenous iron sucrose administration in CKD patients - a study from a tertiary care hospital in North India. Indian J Nephrol 2006;16:129.

7. Chandler G, Harchowal J, Macdougall IC. Intravenous iron sucrose: establishing a safe dose. Am J Kidney Dis 2001 Nov;38(5):988-991.
8. Bashiri A, Burstein E, Sheiner E, Mazor M. Anemia during pregnancy and treatment with intravenous iron: Review of the literature. Eur J Obstet Gynecol Reprod Biol 2003 Sep;110(1): 2-7.

9. Al-Momen AM, Huraib SO, Mitwalli AH, Al-Wakeel J, AlYamani MJ, Abu-Aisha H, Said R. Intravenous iron saccharate in hemodialysis patients receiving r-HuEPO. Saudi J Kidney Dis Transplant 1994 Apr-Jun;5(2):168-172.

10. Aggarwal HK, Tziviskou E, Bellizzi V, Khandelwal M, Moupas L, Bargman JM, Jassal SV, Oreopoulos DG. Prolonged administration over six hours of large doses of intravenous iron saccharate $(500 \mathrm{mg})$ prevents severe adverse reactions in peritoneal dialysis patients. Perit Dial Int 2002 Sep-Oct;22(5): 636-637.

11. Blaustein DA, Schwenk MH, Chattopadhyay J, Singh H, Daoui R, Gadh R, Avram MM. The safety and efficacy of an accelerated iron sucrose dosing regimen in patients with chronic kidney disease. Kidney Int Suppl 2003 Nov;87:S72-S77. 